\title{
Competências de enfermeiros nos cuidados críticos de crianças submetidas a transplante de células-tronco hematopoéticas
}

\author{
Marianna Ferreira ${ }^{1}$, Lucila Castanheira Nascimento ${ }^{2}$, \\ Fernanda Titareli Merizio Martins Braga ${ }^{3}$, Fernanda Machado Silva-Rodrigues ${ }^{4}$
}

\footnotetext{
${ }^{1}$ Enfermeira, Mestre em Enfermagem em Saúde Pública. Ribeirão Preto, SP, Brasil. Email: marianna.ferreira@gmail.com.

${ }^{2}$ Enfermeira, Doutora em Enfermagem. Professora Associada da Escola de Enfermagem de Ribeirão Preto da Universidade de São Paulo. Ribeirão Preto, SP, Brasil. E-mail: lucila@eerp.usp.br

${ }^{3}$ Enfermeira, Doutora em Enfermagem. Enfermeira do Departamento de Enfermagem Geral e Especializada da Escola de Enfermagem de Ribeirão Preto da Universidade de São Paulo. Ribeirão Preto, SP, Brasil. E-mail: titareli@eerp.usp.br

${ }^{4}$ Enfermeira, Mestre em Enfermagem em Saúde Pública. Discente do Programa Interunidades de Doutoramento em Enfermagem da Escola de Enfermagem e pela Escola de Enfermagem de Ribeirão Preto da Universidade de São Paulo. Ribeirão Preto, SP, Brasil. E-mail: fmachadosilv@gmail.com.
}

Recebido: 18/11/2016.

Aceito: 22/05/2017.

Publicado: 24/11/2017.

\section{Como citar esse artigo:}

Ferreira M, Nascimento LC, Braga FTMM, Silva-Rodrigues FM. Competências de enfermeiros nos cuidados críticos de crianças submetidas a transplante de células-tronco hematopoéticas. Rev. Eletr. Enf. [Internet]. 2017 [acesso em:_____ ] 19:a29. Disponível em: http://dx.doi.org/10.5216/ree.v19.43604.

\section{RESUMO}

Estudo descritivo, com análise qualitativa dos dados, a fim de identificar e analisar experiências e competências necessárias ao enfermeiro no atendimento à criança transplantada que demanda cuidados críticos. Foram entrevistados nove enfermeiros. Os dados foram analisados segundo os procedimentos para análise qualitativa de conteúdo e, em seguida, elaboraram-se os temas: Cuidados críticos à criança transplantada: duplo desafio para o enfermeiro; Competências do enfermeiro para assistência à criança grave submetida a transplante de células-tronco hematopoéticas (TCTH). As competências identificadas fundamentaram-se em conhecimento científico, habilidades e aptidões e estão relacionadas ao conhecimento específico sobre TCTH pediátrico; habilidades técnicocientíficas, interacionais e de comunicação; gerenciamento de recursos materiais e equipamentos; controle emocional, empatia e liderança. Tais competências auxiliam na construção de um perfil específico para o cuidado oferecido a esta clientela, com vistas ao sucesso terapêutico.

Descritores: Enfermagem Pediátrica; Cuidados Críticos; Transplante de Células-Tronco Hematopoéticas; Competência Profissional; Enfermeiras e Enfermeiros

\section{INTRODUÇÃO}

O Transplante de Células-Tronco Hematopoéticas (TCTH) é uma importante opção terapêutica para crianças com doenças oncológicas, hematológicas e imunológicas ${ }^{(1-2)}$. Existem basicamente três tipos de transplante: autólogo, singênico e alogênico, denominados de acordo com a origem das células-tronco, ou 
seja, se provenientes do próprio paciente, de irmão gêmeo univitelino ou doador aparentado ou não ${ }^{(3)}$. Tratase de uma modalidade terapêutica prolongada, de alta especificidade e complexidade, com taxa de mortalidade significativa ${ }^{(2)}$. Requer unidade hospitalar exclusiva e equipe multiprofissional capacitada para atender a criança transplantada ${ }^{(4)}$.

O TCTH pode representar a única possibilidade de cura para crianças com doenças graves. Entretanto, o procedimento está relacionado a complicações e depende do estado clínico anterior ao transplante. Os cuidados críticos destinam-se a crianças que se tornam clinicamente instáveis durante o tratamento ou em decorrência dele, sendo que algumas apresentarão comprometimento de órgãos vitais, infecções sistêmicas e Doença do Enxerto-Contra-Hospedeiro (DECH) e, por isso, se beneficiam dos cuidados em unidade de terapia intensiva pediátrica (UTI Pediátrica) ${ }^{(5)}$.

O trabalho de enfermagem em unidade de TCTH abrange competências técnicas específicas, recursos técnico-científicos e elementos de comunicação que contribuem para o sucesso terapêutico. Além disso, o atendimento humanizado, seguro e individualizado à criança e à família deve ser prioritário ${ }^{(2,6)}$. 0 enfermeiro deve sistematizar e individualizar o cuidado ao cliente em todas as fases do transplante, desde a indicação, admissão hospitalar até o acompanhamento ambulatorial, diferenciando cada fase e intervindo adequadamente em cada uma delas ${ }^{(2,7)}$.

$\mathrm{Na}$ literatura relacionada à enfermagem pediátrica e o TCTH predominam publicações voltadas à prevenção de infecções, cuidados com cateteres, complicações pós-transplante, e a qualidade de vida de crianças submetidas ao $\mathrm{TCTH}^{(2-3,5)}$. Não há menção às competências ligadas à formação do enfermeiro atuante nesta área, principalmente com paciente pediátrico crítico. Assim, a questão norteadora do estudo foi: "Quais as competências de enfermagem necessárias no atendimento de crianças submetidas ao TCTH e as especificidades desse cuidado em situações críticas, na ótica dos enfermeiros?". Nessa perspectiva, este estudo objetivou identificar e analisar experiências dos enfermeiros acerca das competências necessárias para o atendimento a crianças submetidas a TCTH que demandam cuidados críticos.

\section{MÉTODO}

Estudo descritivo, com análise qualitativa dos dados, realizado em Unidades de Transplante de Medula Óssea e Terapia Imunológica de um hospital universitário localizado no interior do estado de São Paulo, Brasil. Ambas realizam TCTH em adultos e pediátricos, desde a incorporação de leitos para essa clientela no ano de 2009. Entretanto, uma delas apresenta menor número de internações pediátricas, pois são realizados TCTH autólogos para doenças autoimunes, as quais possuem menor incidência na infância.

A pesquisa foi aprovada pelo Comitê de Ética em Pesquisa da instituição onde foi desenvolvida, conforme Resolução 466/2012 do Conselho Nacional de Saúde ${ }^{(8)}$ (Protocolo no 166/2016). Elaborou-se o Termo de Consentimento Livre e Esclarecido (TCLE) que, em linguagem clara e acessível, informou aos participantes os objetivos da pesquisa e procedimentos para coleta de dados; possíveis constrangimentos ou benefícios, garantindo total sigilo e respeito ao desejo de participarem ou não do estudo, voluntariamente. 
Anteriormente à coleta de dados, o TCLE foi apresentado, lido e discutido com cada potencial participante. Àqueles que concordaram em integrar o estudo, foi solicitada a assinatura, afirmando sua participação na pesquisa e autorizando a gravação da respectiva entrevista.

Participaram enfermeiros com experiência profissional de, no mínimo, um ano; atuantes em unidades de TCTH da referida instituição há mais de seis meses e que prestavam assistência a crianças transplantadas nas diferentes fases do tratamento. O convite aos participantes para integrar a pesquisa se deu continuamente, até que o conjunto de dados empíricos se mostrou redundante ${ }^{(9)}$, revelando-se suficiente para responder ao objetivo da pesquisa e à compreensão do fenômeno estudado.

Foram conduzidas entrevistas semiestruturadas, audiogravadas, em um único encontro, com duração média de 23 minutos, para compreender as experiências dos participantes sobre competências profissionais para o cuidado crítico a crianças submetidas a TCTH. Foram realizadas durante o mês de junho/2016, nas dependências das unidades, em espaço privativo, respeitando-se os horários previamente acordados com cada profissional, não prejudicando a dinâmica de trabalho.

Como aproximação inicial, os entrevistados foram incentivados a contar sobre o que consideravam cuidados críticos a estas crianças. Em seguida, foram abordadas as competências do enfermeiro necessárias para o cuidado de crianças transplantadas que demandam cuidados críticos. Para caracterizar o perfil dos participantes, foram coletados: idade, tempo de formação, titulação e tempo de experiência com TCTH.

O processo de análise se deu de forma concomitante à coleta dos dados. As entrevistas foram transcritas na íntegra após sua realização, preservando-se os discursos dos participantes, e submetidas aos procedimentos para análise qualitativa de conteúdo ${ }^{(10)}$. Procedeu-se inicialmente à leitura exaustiva do material empírico, identificando palavras, frases e conceitos de interesse. Em seguida, os dados foram organizados em temas, com base em unidades de significado previamente identificadas.

Para ilustrar os temas, optou-se por selecionar trechos dos discursos dos participantes, os quais foram representados pela letra " $E$ ", seguida de um número sequencial de ingresso na pesquisa.

\section{RESULTADOS E DISCUSSÕES}

Participaram nove enfermeiros, com idades entre 31 e 49 anos. Destes, um era do sexo masculino e oito do feminino, o que corrobora o perfil histórico predominantemente feminino da profissão e os dados atuais de pesquisas sobre o perfil da enfermagem no Brasil $^{(11)}$.

Quanto à formação, todos eram graduados há mais de cinco anos; dois possuíam apenas a graduação; dois realizaram cursos de especialização lato sensu, um deles mestrado; três realizaram tanto curso de especialização lato sensu como mestrado; e um entrevistado possuía especialização lato sensu e doutorado. Cinco participantes possuíam tempo de experiência profissional em unidades de TCTH entre um e cinco anos; um tinha atuação profissional superior a cinco anos e inferior a 10 anos, e três apresentavam mais que 10 anos de trabalho na área da enfermagem.

A análise qualitativa dos dados empíricos permitiu identificar dois temas: Cuidados críticos à criança 
transplantada: um duplo desafio para o enfermeiro; e Competências do enfermeiro para a assistência à criança grave submetida a TCTH.

\section{Cuidados críticos à criança transplantada: duplo desafio para o enfermeiro}

Cuidar desta clientela representou um duplo desafio ao enfermeiro, pela necessidade de lidar tanto com as especificidades do ser criança, quanto com as demandas do paciente transplantado em cuidados críticos.

O processo de TCTH foi considerado crítico, independentemente da população e faixa etária envolvidas, pois é um tratamento de alto risco que requer atendimento diferenciado e intensivo. Outros participantes consideraram-no crítico apenas diante de algum tipo de instabilidade hemodinâmica, com funções vitais comprometidas, como ilustrado abaixo:

Eu acho que cuidados críticos começam no momento em que ela [criança] apresenta alguma descompensação (...), no momento de uma febre, que pode ser simples e pontual, mas também pode ser o começo, por exemplo, de uma septicemia. (E2)

Eu penso que atendimento crítico é quando acontece algum tipo de instabilidade hemodinâmica ou quando apresenta alteração clínica que requeira um atendimento mais específico. (E7)

Nessa mesma perspectiva, enfermeiros caracterizaram cuidado crítico como aquele que requer assistência de enfermagem rigorosa e necessidade transfusional aumentada, de monitorização e de uso de medicamentos endovenosos. A maioria dos enfermeiros percebeu o TCTH pediátrico como cuidado crítico e específico; apenas um apresentou dificuldade para conceituar e/ou caracterizar cuidado crítico no caso de crianças submetidas a TCTH.

O TCTH é considerado uma modalidade terapêutica de alto risco e o paciente submetido a este procedimento é, muitas vezes, comparado àquele que necessita de cuidados intensivos, principalmente pela gravidade e necessidade de aparatos tecnológicos ${ }^{(12)}$. Apesar dos avanços relacionados aos exames de histocompatibilidade e regimes de condicionamento mais seguros, o transplante ainda apresenta elevadas taxas de complicações, com alto índice de mortalidade, relacionadas com toxicidade do regime de condicionamento, imunossupressão e doença do enxerto-contra-hospedeiro ${ }^{(1,5)}$. Tais complicações demandam admissão em UTI, aumentando a mortalidade, sobretudo quando há intubação endotraqueal prolongada $^{(1)}$.

Estudo aponta que a proporção de crianças submetidas a este transplante que requerem admissão em UTI pediátrica pode chegar a $44 \%{ }^{(3)}$. Destaca-se a fase do pós-transplante imediato (até 100 dias após a infusão das células-tronco) como a de maior risco, principalmente nos períodos de citopenia, quando é esperado um maior número de eventos adversos relacionados ao TCTH, como infecções, sangramentos, anemias, mucosites, pneumonite intersticial, cistite hemorrágica, dentre outras ${ }^{(5)}$.

Os enfermeiros também foram questionados sobre a frequência com que atendem crianças submetidas a TCTH que requerem cuidados críticos. Sobre isso, os entrevistados apresentaram contradições, 
acentuadas sobretudo por seus conceitos de cuidado crítico, ou seja, para aqueles que entendem que ele se dá quando a criança apresenta algum tipo de instabilidade hemodinâmica, a frequência deste tipo de atendimento é pequena.

Para todos os enfermeiros da pesquisa, a experiência com o atendimento de crianças que necessitaram de cuidados críticos contemplou aspectos relacionados a: receio de atender crianças gravemente enfermas; dificuldade para interpretar o que a criança sente; construção de vínculo e envolvimento emocional com a criança/família, os quais dificultavam o cuidado e o manejo dos sentimentos a ele relacionados. Todos os participantes verbalizaram dificuldades emocionais em lidar com a criança em risco iminente de morte, ver o sofrimento do paciente e ressaltaram o desafio de oferecer apoio à família.

Para a maior parte dos entrevistados, o TCTH pediátrico deveria exigir uma equipe específica, considerando o perfil e a preferência profissional. Muitos referiram que passaram a cuidar de crianças após serem admitidos na unidade e que toda experiência profissional prévia esteve relacionada à população adulta. Apenas um entrevistado mencionou preferir cuidar de crianças. Alguns enfermeiros assinalaram o sentimento de pena em relação à criança e/ou à família.

Eu sempre fugi da pediatria, não gosto de cuidar de criança... Não é que eu não gosto, tenho dó. (E7) Fora o cuidado que é crítico, a parte emocional e psicológica de ver uma criança, uma mãe nessa situação, também é difícil. (E2)

Três depoentes mencionaram dificuldade em atender crianças, principalmente pela dificuldade de interpretar o que elas sentem, como exemplificado abaixo:

A criança, dependendo da faixa etária, não vai conseguir se comunicar claramente. Então, você vai ter que utilizar outros recursos para identificar o que ela tem. Talvez a parte crítica de você avaliar uma resposta à dor ou mesmo com coisas relacionadas a sinais vitais, muda um pouco. (E6)

Alguns profissionais relataram segurança para o atendimento crítico a crianças, apesar de determinadas limitações e dificuldades.

A gente fica com dó da criança, mas consigo ter um controle emocional bom (...). Às vezes fico abalado, mas fica pra mim; acho que não exponho isso. (E1)

Atender uma insuficiência respiratória, enfim, intercorrências clínicas, isso não me assusta. O que me deixa bem incomodada é esse sofrimento que eles passam. (E3)

Pensar no cuidado infantil, sobretudo de crianças em situação crítica, é complexo e demanda sensibilidade para perceber fatores que envolvem relações e inter-relações com família, equipe e criança, considerando os marcos do crescimento e desenvolvimento infantil e as peculiaridades desta clientela ${ }^{(6)}$. Nas unidades de TCTH, assim como naquelas de terapia intensiva pediátrica, por serem espaços de acesso restrito, de grande especificidade, com internações prolongadas e uso de alta tecnologia, as relações próximas e a criação de vínculos estreitos entre profissional-criança-família podem ser vistas como fatores 
limitantes e desgastantes para aqueles que atuam nesse cenário ${ }^{(13,14)}$. Em contrapartida, vínculos positivos auxiliam no planejamento do cuidado e abrem possibilidades de atendimento humanizado, integral e integrado, permitindo melhores resultados do ponto de vista terapêutico.

Crianças que passam por TCTH apresentam condições clínicas graves, que as impedem de brincar ou realizar atividades da vida diária. Permanecem em quartos privativos devido ao risco de infecção e convivem com procedimentos repetitivos, dolorosos e com eventos adversos do tratamento. Há ainda a sensibilidade emocional, por vezes expressa por pânico, ansiedade e inquietação, condição que mobiliza recursos técnicos e emocionais dos enfermeiros ${ }^{(13)}$. Testemunhar essas condições impostas pela condição clínica das crianças reitera o duplo desafio vivenciado pelo enfermeiro no cotidiano de sua prática.

\section{Competências do enfermeiro para assistência à criança grave submetida a TCTH}

Os participantes deste estudo identificaram habilidades específicas que amparam o trabalho do enfermeiro no TCTH pediátrico, as quais compreendem a singularidade da criança e do tratamento, a disponibilidade de recursos técnico-científicos, de elementos de comunicação e interação que garantam manejo do tratamento proposto e atendimento seguro e humanizado, tanto da criança como da família, como ilustrado a seguir:

Eu acho que, além desse conhecimento técnico do enfermeiro, ele precisa saber da doença, porque têm doenças que são especificas da infância, determinadas leucemias. Ele precisa saber quais os possíveis problemas que essa criança pode ter, tanto ligado à doença quanto ao condicionamento que está fazendo. (E3)

Ele [o enfermeiro] tem que ter uma bagagem de raciocínio clínico, raciocínio científico; habilidade de conhecer parâmetros de sinais vitais da criança; discernimento de saber se aquela complicação é esperada, além de bom senso. (E9)

Os entrevistados citaram a necessidade de conhecimento teórico específico e atualizado, além da capacidade de prever situações clínicas graves:

Você sempre tem que ter a visão do agravamento da criança; é você tentar sempre estar um passo antes. Como a gente fica muito em contato com a criança, a gente tem, junto com a mãe, mais ferramentas para avaliar uma alteração da criança, mais rápido que o médico, por exemplo. (E7)

O enfermeiro precisa planejar, ou seja, lidar sempre com a previsão, tem que prever o que pode acontecer (...), $e$ relacionar com as fases do transplante. O que aquele quimioterápico pode trazer de complicação? (...) O que é imunossupressor? A infusão de medula? E o pós? Tem que estar respaldado e amparado todos os dias com o planejamento. (E9)

É importante também que o profissional atuante em unidade de TCTH planeje a assistência por meio de modelo assistencial sistemático e individualizado, que assista à criança em todas as fases do transplante, diferenciando riscos, especificidades e propondo intervenções adequadas em cada uma delas ${ }^{(2)}$. A capacidade de observar sinais de alerta, relacionar conhecimentos teóricos e prática, identificar o problema de enfermagem, planejar o cuidado, implementar a assistência e avaliá-la são elementos que constituem a Sistematização da Assistência de Enfermagem (SAE) e norteiam a atenção às necessidades individuais do 
paciente e sua família ${ }^{(15)}$.

Alguns enfermeiros também citaram a necessidade de treinamentos para toda equipe de enfermagem, para melhorar o atendimento de urgência e emergências pediátricas:

Eu acho que é muito importante o treinamento da equipe, atualização do atendimento e das principais intercorrências do transplante, voltado para criança, porque é diferente mesmo. (E2) Habilidade técnica em relação ao cuidado de urgência e emergência, saber bem claro o esperado para cada faixa etária, doses especificas de medicações, ter noção dos tipos de dispositivos para cada idade, porque numa criança crítica, você saber qual tipo de cânula vai usar, qual dispositivo, você otimiza o atendimento. (E6)

Um dos depoentes mencionou que, além do planejamento da assistência, os enfermeiros devem apresentar habilidades gerenciais, principalmente quanto à provisão de materiais e equipamentos necessários para atendimentos críticos. Um deles afirmou que:

O enfermeiro, antes de uma urgência propriamente dita, tem que gerenciar a unidade em termos de materiais, para ver se tem tudo, de modo a atender às necessidades do paciente em todas as situações (E7).

É característica do processo de trabalho em enfermagem a concomitância/complementaridade da dimensão assistencial e gerencial. Para o desempenho das atividades profissionais, o enfermeiro deverá constantemente articular ambas as dimensões ${ }^{(16)}$.

Os enfermeiros verbalizaram maior segurança em relação à competências ligadas às habilidades técnicas, pois estas podem ser aprendidas e absorvidas na prática clínica diária, diferentemente daquelas relacionadas a aptidões e escolhas vocacionais, como: Saber lidar com a população pediátrica; controle psicológico e emocional, sensibilidade/empatia e comunicação com a família, como exemplificado abaixo:

Habilidades para lidar com criança, isso é com o tempo; de saber puncionar; como fazer a criança ser submetida a um procedimento sem sofrer tanto; saber conversar com a criança e com a mãe. (E3)

A construção de competências está vinculada tanto à escolaridade como a processos de aprendizagem informais que ocorrem em momentos e espaços distintos ${ }^{(17)}$. Desse modo, com base na formação e nas experiências dos enfermeiros, foram identificadas competências necessárias para o atendimento de crianças transplantadas que demandam cuidados críticos. Na Figura 1 estão sintetizadas as competências que, segundo os enfermeiros, são essenciais para o atendimento de crianças submetidas a TCTH no contexto dos cuidados críticos.

Observou-se que as competências apontadas como essenciais baseiam-se em: conhecimentos, habilidades e aptidões, descritos na literatura como eixos estruturantes da competência, ou seja, referemse a recursos pessoais que refletem como são executadas as tarefas ${ }^{(16-18)}$. Destaca-se que tais eixos se interligam a experiências pessoais, nas quais o sujeito é capaz de mobilizar recursos cognitivos como saberes, práticas e informações em seu ambiente de trabalho, proporcionando-lhe momentos únicos e individuais de aprendizado $^{(16-17)}$. 
Figura 1: Competências essenciais para o atendimento de crianças submetidas a TCTH que demandam cuidados críticos, segundo os participantes do estudo.

\begin{tabular}{|l|}
\hline Competências essenciais \\
\hline 1. Conhecimentos sobre TCTH pediátrico. \\
\hline 2. Habilidades técnicas em relação ao cuidado da criança. \\
\hline 3. Conhecimentos para observar sinais de alerta. \\
\hline 4. Sistematização do cuidado de enfermagem (SAE). \\
\hline 5. Competência gerencial (adequação de recursos materiais e equipamentos). \\
\hline 6. Conhecimentos específicos sobre crescimento e desenvolvimento infantil. \\
\hline 7. Oferecimento de apoio familiar. \\
\hline 8. Controle psicológico e emocional. \\
\hline 9. Trabalho em equipe. \\
\hline 10. Sensibilidade e empatia. \\
\hline 11. Liderança. \\
\hline
\end{tabular}

A aquisição de competências depende da relação entre conhecimento e experiências individuais ${ }^{(18)}$. Os seres humanos crescem por meio da progressiva aquisição de conhecimentos, resultado de constantes análises, elaboração e interpretação das experiências. Já as competências vocacionais não parecem ser resultado de qualquer treinamento, mas sim do encontro das experiências com o conhecimento teórico. Assim, as competências vocacionais se formam pelo contínuo autocontrole que o indivíduo apresenta em relação ao uso de seus recursos próprios e se desenvolvem pela aplicação do conhecimento ${ }^{(18)}$. Portanto, apreende-se que as dificuldades dos participantes referem-se à sua limitada competência vocacional e não à falta de conhecimento científico e habilidades técnicas para assistir à população pediátrica. Observa-se, ainda, que as competências apontadas pelos enfermeiros como essenciais são, por vezes, mais vocacionais que adquiridas, como a comunicação interpessoal, algo essencial para a abordagem da criança, familiares e equipe de saúde, como ilustrado abaixo:

Uma habilidade que precisamos ter, além de técnica e conhecimento, é saber abordar a criança e o adulto acompanhante. Nesses cursos, aprendemos sobre isso, mas acho que a maior experiência que eu já tive foi aqui mesmo no dia a dia, aprendendo com as mães. (E3)

(...) acho que você tem que ter prática na habilidade de relacionamento interpessoal, de empatia. (E6)

Embora este estudo tenha sido desenvolvido por meio de recrutamento de participantes de uma única instituição de saúde, pode ser considerado uma importante iniciativa, capaz de disparar novas questões para a prática e pesquisa que fomentem reflexões sobre o perfil do enfermeiro que atua em TCTH pediátrico. Os enfermeiros possuem diferentes graus de formação e a organização do trabalho se dá pela divisão de tarefas, garantindo-Ihes o papel de detentores do saber e controladores do processo de trabalho ${ }^{(16)}$, o que justifica a necessidade de competências embasadas em habilidades de comunicação e liderança, ressaltadas pela maioria dos participantes.

Assim, para assegurar atendimento de enfermagem integral a crianças submetidas a TCTH em situação crítica, faz-se necessário recursos intrínsecos e extrínsecos relacionados a conhecimentos, habilidades e aptidões $^{(18-19)}$, ou seja, o profissional deve dispor de competências não só para o atendimento pautado em 
conhecimento técnico-científico, mas que considere também a criança e a família, respeitando os seus próprios limites emocionais e suas aptidões pessoais para lidar com um público tão peculiar, em situações de instabilidade clínica.

\section{CONSIDERAÇÕES FINAIS}

Foi possível concluir que a intervenção educativa colaborou positivamente no conhecimento teórico dos profissionais de enfermagem sobre parada cardiorrespiratória, no grupo estudado.

Além disso, cabe destacar que se faz necessário o desenvolvimento de mais estudos sobre a temática abordada, pois pesquisas deste cunho podem subsidiar as estratégias gerenciais que visam qualificar o cuidado, fomentando a apropriação de conhecimento técnico-científico sólido por parte dos profissionais. Dessa mesma forma, é preciso compreender qual a influência das intervenções educativas (e fatores associados) não só no conhecimento teórico dos profissionais de Enfermagem, mas também em suas práticas laborais, quando da atuação em situações de PCRIH.

\section{REFERÊNCIAS}

1. Soubani AO. Critical care considerations of hematopoietic stem cell transplantation. Crit Care Med [Internet]. 2006 [acesso em: 23 out. 2017];34(9 Suppl):S251-67. Disponível em: http://dx.doi.org/10.1097/01.CCM.0000231886.80470.B6.

2. Lima K, Bernardino E. Nursing care in a hematopoietic stem cells transplantation unit. Texto contexto - enferm. [Internet]. 2014 [acesso em: 23 out. 2017];23(4):845-53. Disponível em: http://dx.doi.org/10.1590/010407072014000440013.

3. Chima RS, Daniels RC, Kim MO, Li D, Wheeler DS, Davies SM, et al. Improved outcomes for stem cell transplant recipients requiring pediatric intensive care. Pediatr Crit Care Med [Internet]. 2012 [acesso em: 23 out. 2017];13(6):e336-42. Disponível em: http://dx.doi.org/10.1097/PCC.0b013e318253c945.

4. Portaria № 931 do Ministério da Saúde, de 02 de maio de 2006 (BR). Regulamento técnico para transplante de células progenitoras hematopoéticas. Diário Oficial da União. 12 ago 2016.

5. Ball LM. Intensive care and outcome in children undergoing haematopoietic stem cell transplantation. Rep Pract Oncol Radiother [Internet]. 2007 [acesso em: 23 out. 2017];12(3):171-4. Disponível em:

https://doi.org/10.1016/S1507-1367(10)60054-5.

6. Dias SMZ, Motta MGC. Práticas e saberes do cuidado de enfermagem à criança hospitalizada. Ciênc. cuid. saúde [Internet]. 2008 [acesso em: 23 out. 2017];3(1):41-54. Disponível em:

http://www.periodicos.uem.br/ojs/index.php/CiencCuidSaude/article/view/5515.

7. Serrano MTP, Costa ASMC, Costa NMVN. Cuidar em Enfermagem: como desenvolver a(s) competência(s). Rev. Enf. Ref. [Internet]. 2011 [acesso em: 23 out. 2017];serllI(3):15-23. Disponível em:

http://www.scielo.mec.pt/scielo.php?script=sci_arttext\&pid=S0874-02832011000100002\&lng=pt\&nrm=iso\&tlng=pt.

8. Resolução № 466 do Conselho nacional de Saúde, de 12 de dezembro de 2012 (BR). Aprova as diretrizes e normas regulamentadoras de pesquisa envolvendo seres humanos. Diário Oficial da União. 12 ago 2016.

9. O’Reilly M, Parker N. Unsatisfatory saturation: a critical exploration of the notion of saturated sample sizes in qualitative research. Qual Res. 2012; 13(2):190-97.

10. Mayring P. Qualitative content analysis. Forum Qual Soc Res. 2000;1(2): 1-10.12.

11. Fundação Oswaldo Cruz. Pesquisa da Fiocruz, por iniciativa do Conselho Federal de Enfermagem que traça o perfil da enfermagem no Brasil [Internet]. 2016 [acesso em: 14 ago. 2016]. Disponível em: http://portal.fiocruz.br/pt-

br/content/pesquisa-inedita-traca-perfil-da-enfermagem-no-brasil 
12. Silva JB. Eventos adversos e carga de trabalho de enfermagem em pacientes submetidos ao transplante de célulastronco hematopoiéticas: estudo de coorte [tese]. São Paulo: USP; 2015.

13. Braga LC, Sousa FGM, Santos MH, Santos DMA. Demandas de atenção do enfermeiro em unidade de terapia intensiva pediátrica: uma investigação qualitativa. Arq Ciênc Saúde. 2015;22(4):52-57.

14. Huang YP, Kellett U, Wang SY, Chang MY, Chih HM. Experience of nurses caring for child with hematopoietic stem cell transplantation in general pediatric ward. Cancer Nurs. 2014;37(5):32-9.

15. Garcia, TR. Sistematização da assistência de enfermagem: aspecto substantivo da prática profissional. Esc Anna Nery. 2016;20(1):205-6.

16. Camelo SHH. Competência profissional do enfermeiro para atuar em unidade de Terapia Intensiva: uma revisão integrativa. Rev Latino Am Enfermagem. [Internet]. 2012 [acesso em: 18 ago 2016];20(1). Disponível em:

http://dx.doi.org/10.1590/S0104-11692012000100025.

17. Camelo SHH, Angerami ELS. Competência profissional: a construção de conceitos, estratégias desenvolvidas pelos serviços de saúde e implicações para a enfermagem. Texto Contexto Enferm. 2013;22(2): 552-60.

18. Fleury MTL, Fleury A. Construindo o conceito de competência. RAC. 2001;(esp):183-96.

19. Meghnagi S. The contexts of training. In: Cedefop. Agora VII - Working time, training time. Luxembourg: Cedefop; 2003. p.59-66. 